\title{
The concept of usage HRTSIM as a device for setting and certification of AVR
}

\author{
Alisher Askarov ${ }^{1, *}$, and Nikolay Ruban ${ }^{1}$ \\ ${ }^{1}$ National Research Tomsk Polytechnic University, 634050 Tomsk, Russia
}

\begin{abstract}
This paper presents the analysis of application Hybrid RealTime Power System Simulator (HRTSim), developed at National Research Tomsk Polytechnic University, as a device for setting and certification of automatic voltage regulators (AVR) for synchronous generators. The simulation results demonstrate that the proposed hardware-software complex (HSC) can be used for presented aim.
\end{abstract}

\section{Introduction}

The reliability level of the United Power System (UPS) of Russia is determined, among other factors, by reliability and operational characteristics of power facilities, devices and control systems, including the characteristics of the modern microprocessor devices of automated control, regulation, protection and automation.

However, the devices used in practice may have algorithmic or programming errors. Also they are not always adapted to the operating conditions in a real power system. That all leads to increase in the number of technological disturbances in power systems and decrease the reliability of parallel operation of power plants and power systems, as a whole. In particular, disconnection of a generating unit became more frequent due to the loss of excitation (incorrect operation of AVR) in power plants, moreover, due to the fact that interconnecting mains are usually "weak" and heavily loaded, it in turn causes the lowfrequency $(0,1-0,5 \mathrm{~Hz})$ fluctuations with large amplitude in power systems and leads to a non-effective operation of AVR and false operation of protective relays [1-3].

Therefore, microprocessor devices of AVR used in new or modernized power facilities must be tested in conditions close to the conditions of future operation to ensure system reliability of the UPS of Russia [4], which, moreover, is obligatory, according to the standards of JSC "SO UPS" [5]. In accordance with [5], testing of the AVR settings is carried out - either on a physical model of the power system, either on a mathematical model of the power system using a hardware-software complex of real-time power systems simulation.

But at this moment, the certification of AVR is exclusively performed on the physical model of electric power system.

\footnotetext{
* Corresponding author: askalibah@gmail.com
} 


\section{Research aim}

In connection with the foregoing, the aim of this work is the development of the first domestic HSC for setting and certification of AVR of synchronous generators on the basis of Hybrid Real-Time Power System Simulator, developed at National Research Tomsk Polytechnic University, which after adaptation will be meet requirements of JSC "SO UPS" and can be used to solve the set aim [6].

HRTSim is a multiprocessor system based on a modern concept of hybrid simulation of power system and has a number of advantages over widely used digital systems:

1. excluded regimes and processes decomposition;

2. high simulation accuracy, limited only by instrumental error, which depends on the component base;

3. ensures continuous methodically exact solution of adequate three-phase mathematical models of facilities and EPS as a whole in real-time;

4. has no limits on the volume of the simulated power system and the depth of the models.

Properties and possibilities of this HSC allow to use it to solve a wide range of different objectives, which are confirmed by the results of many researches [7-10].

\section{Materials and methods}

The mathematical model of AVR, shown in Fig. 1 and used in HRTSim, has been used as the basis for the research.

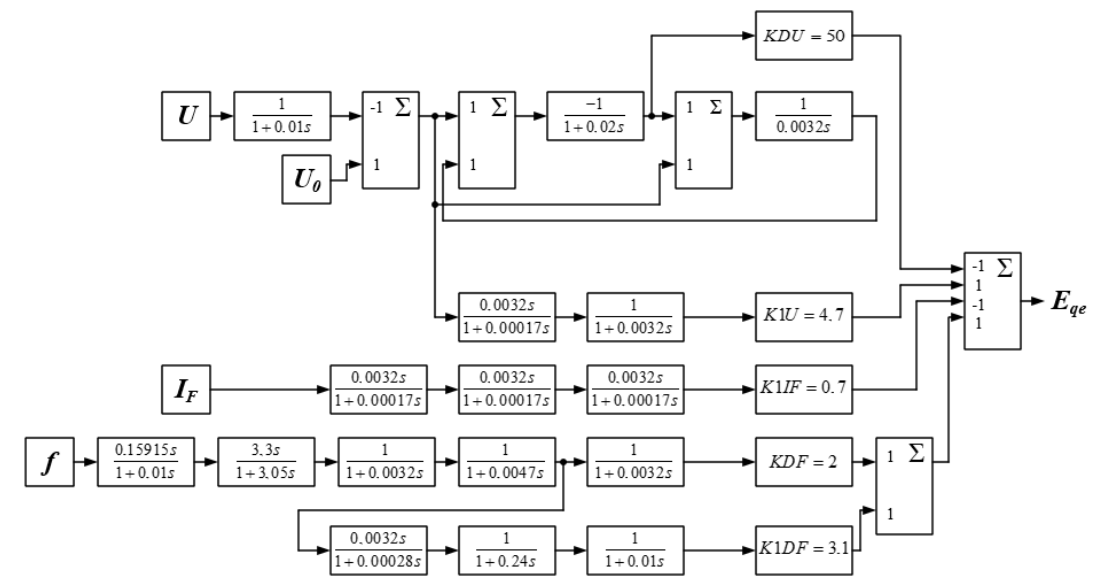

Fig. 1. The mathematical model of AVR, realized in HRTSim.

This structural scheme of AVR mathematical model synthesized on the basis of the analysis of different existing excitation systems and AVR [11, 12], that allows to consider significant factors and elements for the adequate simulation of regulators.

Taking into account the possibility of changing, regulating, implementation of additional channels, resetting all coefficients and parameters in the presented AVR model, this mathematical model allows to adequately and fully simulate the functioning of all types of excitation systems and AVR.

The model of the power system for AVR testing (Fig. 2), presented in [5] and realized in HRTSim, has been used as the basic scheme for researches. As the simulated generator with the testing AVR has been used the generator " $G-1 \_1$ ". 


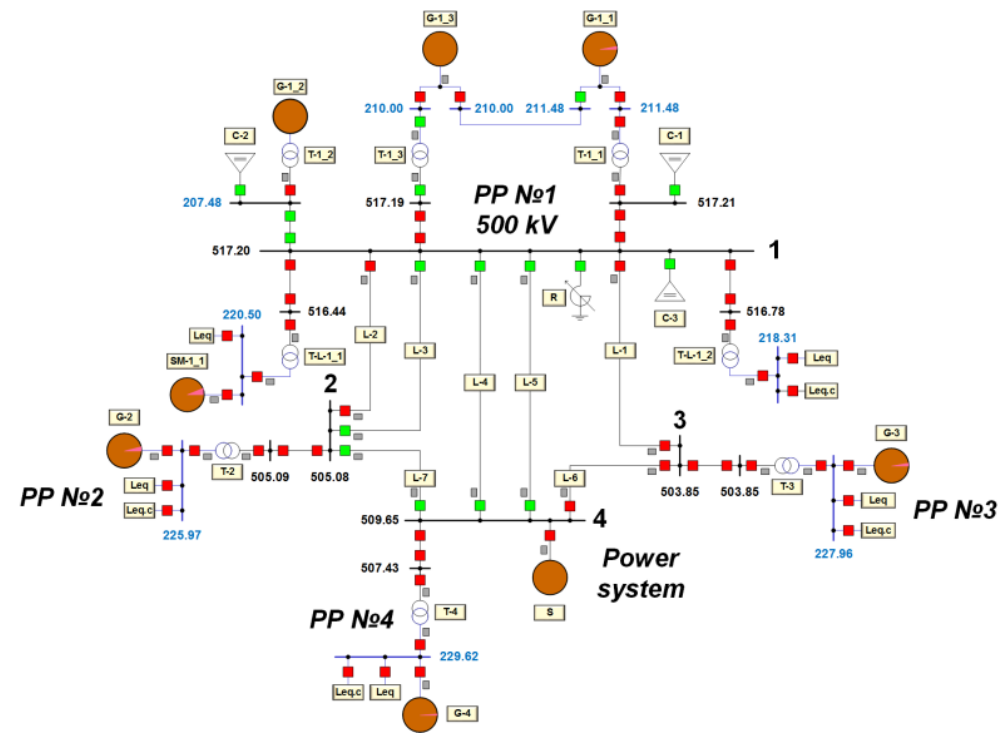

Fig. 2. The model of the power system for AVR testing, realized in HRTSim, according to [5].

As a check of the correct operation of the AVR of synchronous generators has been performed test disturbances, according to the standard "SO UPS" [5]. In this paper presented the results of the next test disturbance - a step changing of voltage on the busbars of power station, where installed testing AVR, by connecting a capacitance $C 1=188$ MVAr to the busbars of this station (the busbars $500 \mathrm{kV}$ PP No.1). Example of the correct operation of AVR at the entrance to the area of minimum excitation limit (MEL) and exit from the area of MEL, according to [5], is shown in Fig. 3a.

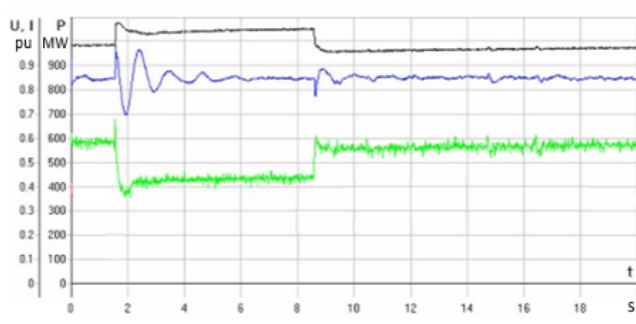

a).

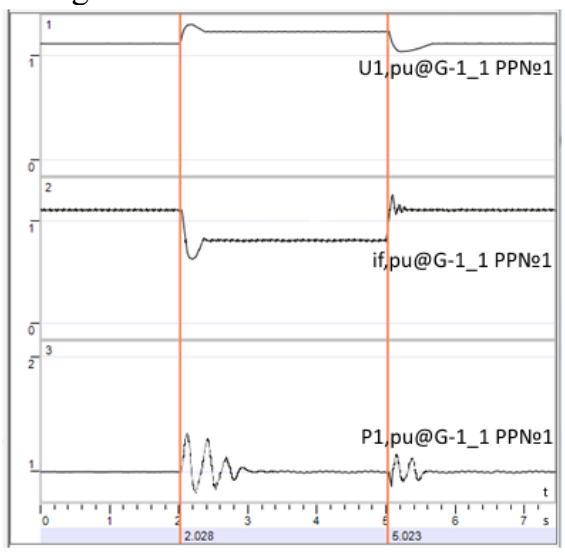

b).

Fig. 3. Oscillograms of the AVR operation in case of MEL.

In this experiment has been verified the correctness of the AVR operation in the regime of minimum excitation limit. As can be seen from the oscillograms (Fig. 3b), when the balance of reactive power changed under connecting of capacitance, the voltage on the busbars of power plants increased and the excitation current reduced to the minimum value, what ensures the functioning of MEL, which does not allow violation of the static stability of the power system. 


\section{Analysis of the obtained results}

In this article for the first time proposes to use HRTSim for setting and certification of AVR, which combines the advantages of physical and mathematical simulation of power systems.

Further work lies in the development of the communication interface between HRTSim and real AVR devices and also in the modernization of the mobile version of the complex for onsite setting and certification, which in turn would reduce the time and cost of work. This development especially effective for:

- hydropower plants, where the hydro-generators and characteristics of power plant are purely individual;

- $\quad$ nuclear power plants, where full-scale and correct setting of AVR is required for security reasons.

Also the relevance of this work is confirmed by many Russian companies such as JSC “Rosenergoatom Concern”, PJSC “RusHydro”, PJSC “INTER RAO” [13].

This work was supported by the Ministry of Education and Science of the Russian Federation under the governmental grant "Science" No. 13.5852.2017/BCH (Development of the concept for comprehensive validation of calculating modes and processes in electric power system and tools of its realization).

\section{References}

1. A. Suvorov, Y. Borovikov, A. Gusev, A. Sulaymanov, M. Andreev, N. Ruban, R. Ufa, Electr. Eng. J. 99, 959 (2017), DOI: 10.1007/s00202-016-0464-4

2. N. S. Kumar, J. Gokulakrishnan, Int J. electr. power energy syst. 33, 1172 (2011)

3. A. Ghorbani, B. Mozafari, S. Soleymani, A.M. Ranjbar, Turk. J. Elec. Eng. Comp. Sci. 24, 2575 (2016)

4. A. Gusev, A. Suvorov, A. Sulaymanov, MATEC Web Conf. 37, 01023 (2015), DOI: $10.1051 /$ matecconf $/ 20153701023$

5. STO 59012820.29.160.20.001-2012. Requirements to excitation systems and automatic voltage regulators of synchronous generators

6. A. A. Suvorov, A. S. Gusev, A. O. Sulaymanov, O. V. Suslova, MATEC Web Conf. 91, 01052 (2017), DOI: 10.1051/matecconf/20179101052

7. A. S. Gusev, A. A. Suvorov, A. O. Sulaymanov, IOP Conf. S. 93, 012016 (2015), DOI: 10.1088/1757-899X/93/1/012016

8. Y. Borovikov, A. Prokhorov, M. Andreev, Proc. 7th Int. Forum Strategic Technol. 341 (2012), DOI: 10.1109/IFOST.2012.6357822

9. A. Prokhorov, Y. Borovikov, M. Andreev, Proc. 7th Int. Forum Strategic Technol. 512 (2012), DOI: 10.1109/IFOST.2012.6357823

10. Y. S. Borovikov, A. Y. Pischulin, R. A. Ufa, IOP Conf. S. 93, 012018 (2015), DOI: 10.1088/1757-899X/93/1/012018

11. H. Zimmer, B. Niersbach, J. Hanson, Proc. 11th IEEE Int. Conf. CPE-POWERENG, 71 (2017)

12. U. K. Verma, S. Banerjee, A. P. Singh. Proc. 3rd Int. Conf. AEEICB, 299 (2017)

13. M. Andreev, A. Sulaymanov, A. Suvorov, MATEC Web Conf. 37, 01001 (2015), DOI: 10.1051/matecconf/20153701001 